\section{UC know-how can boost California wine economy}

IN California, grape cultivation and its value-added agricultural product, wine, are major factors in the state's economy. California wine is valued at $\$ 16.6$ billion retail (see page 12), and total economic activity from the wine industry is estimated at over $\$ 45$ billion. This economic activity has now reached a critical juncture when it is time to evaluate our research investment.

The United States will soon be the largest global wine market. Total consumption has increased by $40 \%$ over the last 10 years, and per capita consumption has grown $23 \%$. However, with per capita consumption at about 2.4 gallons there should be room for additional growth, since most other Western countries consume more. For instance, per capita wine consumption is 5 gallons per year in the United Kingdom and 6.5 gallons in Australia.

With such significant growth potential, U.S. producers are being challenged by wine imports for market share. U.S. wine drinkers have been consuming more imported wine, with imports growing to $27 \%$ of the market in 2005, doubling since 1990. The largest growth in the import market is due to a phenomenal explosion in the importation of Australian wine, which rose by $1500 \%$ over the last 10 years. Australia is poised to become our number one import country in 2007.

The tremendous success of the Australian wine industry is based on a visionary investment partnership between the Australian industry, government and academia. This comprehensive effort includes new and updated vineyard plantings, new production facilities, major marketing campaigns, investments in the education of skilled professionals, and scientific research targeted at matching the qualities of Australian wine to market preferences at affordable prices.

To maintain a competitive and sustainable business position, the U.S. grape and wine industry must strategically invest in the future in these same areas. There have been significant investments in new plantings, for instance in the Central Coast region (see page 11), and some new facilities are being built in those areas to accommodate production. But the investments in education and research have not been comparable to other major wine-producing countries. To address this, there have been calls for increased research funding through various means, and concern has been expressed over the shortage of trained viticulture and enology professionals. Clearly, more can be done in these latter areas.

The recent growth in new winery businesses has far exceeded the capacity of existing educational programs; the situation has become serious enough to stimulate a session on the workforce at the nationwide Unified Wine and Grape Symposium in 2006. Due to a shortage of locally trained individuals, many new hires are from overseas or lack training in viticulture or enology. To address this, we need hard data on market demand, and then we must create a plan to edu-

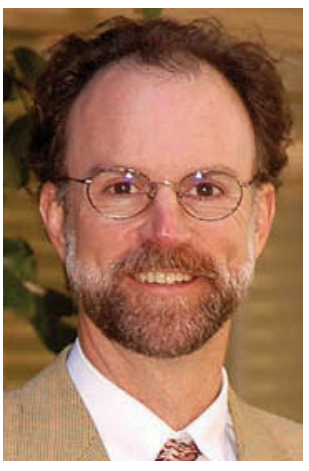

Andrew L. Waterhouse Interim Chair,

Department of Viticulture and Enology, UC Davis

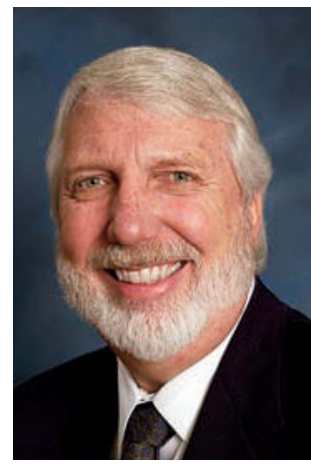

Neal Van Alfen

Dean, College of

Agricultural and Environmental Sciences UC Davis cate the skilled workforce necessary to keep the California wine industry competitive.

Research in California has been funded at lower levels than that of overseas competitors for many years, particularly in contrast to Australia. For the 2007-2008 cycle, for example, less than $\$ 1$ million in competitive funds went to California public institutions for enology research, while the Australian Grape and Wine Research and Development Corporation reported an expenditure of $\$ 20.7$ million, including market analysis.

With its strong historical record in education, research, extension and ongoing education, the University of California can help address these areas of need. A recent study of wine and grape research showed that the United States (largely UC) has a dominant but threatened position, with Australian research output rapidly growing. U.S. research is also recognized as authoritative to others in the field, as it has a very high citation rate. This is a strong research foundation on which to build in the future.

Graduates from UC Davis in the fields of enology and viticulture have been dominant players in the profession for more than 50 years. Graduates are in high demand by vineyard and wine businesses in California, and the wines they produce regularly receive state and national awards. The education delivered offers scientific depth - with an emphasis on critical thinking, problem-solving and life-long learning — and is essential to addressing competitive challenges to California grape and wine businesses. And, Ph.D. graduates become the faculty at other wine and grape programs across the United States, a necessary stimulus to the expansion of a wine culture nationwide. It is important to note that the output of researchtrained viticulture and/or enology graduates, M.S. winemakers and Ph.D. graduates, is constrained by the availability of funded grape and wine research projects.

Investments in education and research are essential to maintain the vitality of the industry. UC can help plan and build a bold future with research on sustainable practices and a new understanding of wine flavor, giving California winegrowers an edge in the market. We stand ready to help the industry strengthen a competitive, capable and flexible workforce, and develop the future educators necessary to sustain this momentum. 